\title{
Knowledge and Attitudes Related to Dental \& Healthcare Ethics Among Dental Practitioners in Delhi, India: A Cross-Sectional Questionnaire Study
}

\author{
Dr. Jyoti Chopra* \\ BDS, M M College of Dental Sciences \& Research, Maharishi Markandeshwar University, Mullana, Ambala, \\ Haryana, India
}

*Corresponding Author: Dr. Jyoti Chopra, BDS, M M College of Dental Sciences \& Research, Maharishi Markandeshwar University, Mullana, Ambala, Haryana, India. Email: jyotichoprabds89@gmail.com

\begin{abstract}
There is a significant increase in research activities in Dental Health of India during recent decades but there is a little evidence of literature about the knowledge and attitudes related to dental and healthcare ethics among dental practitioners. The objective of the study is to assess the knowledge and attitudes of dental practitioners regarding dental and healthcare ethics. A cross sectional questionnaire survey consisting of 27 close ended questions were used to assess knowledge and attitudes in 500 dental practitioners. The resulting data were tabulated and statistically analysed. The results showed that $18 \%$ participants knew about Dental Act formulation year but $29 \%$ were aware that code was revised in $2014.78 \%$ participants were aware that it was unethical for a dental surgeon to refuse a treatment because the patient was HIV positive. $82 \$$ of dentists entertain patients' questions during their visits and $78 \%$ take informed consent in their practice. This study concludes that majority of dental practitioners were aware of dental and healthcare ethics but their usage and moral values need to be given attention. Although recommendations have been made in Dentist act and code of ethics to alter their behaviour but true improvement can be seen after changes in legislation and practice policies, also, the incorporation of an ethical practice curriculum in the initial period of training programmes would be advantageous.
\end{abstract}

Keywords: Ethics, Healthcare ethics, Knowledge, Attitudes, Dental health, Dental act, Code of Ethics

\section{INTRODUCTION}

One of the important components of this universe comprises of legal system. And under which, so many laws, have been particularly enacted to support, protect and promote general public's health. Three major areas that are concerned in the Health and health related laws are Health care, population and environment. [1]

Ethics, a general term, refers to the moral code of conduct in a civil society and their rules, its customs, and beliefs. Since childhood, one learns moral values and social rules that help in moral and social conduct of behaviour and its management. Similarly, health care ethics deal with how health care providers apply a general/ moral code of conducts to patients and with colleagues in a healthcare setting taking into account of their self respect, individually safety and welfare. [2]

Dentistry as a health care profession has come a long way from undifferential professional stage to well known advanced professional stage. During this journey, dentistry has witnessed and accepted changes and/or new concepts simultaneously with rapidly changing technology. [3]

One of the most important characteristics of the profession is to adhere with Code of Ethics. Ethics in dentistry is a set of moral obligations that encompass preformed conduct and judgement imposed by the members of the dental profession. [3]

In today's era of globalisation, a lot of information is accessible to both general public and dental care professionals within hours. Law and legal system can only set minimum standards of professional care and skills.

\section{Materials AND MeTHOD}

The present study was a descriptive, crosssectional, questionnaire based study conducted on dental health professionals of New Delhi (National Capital Region) city in India in august, 2018. Written permissions were obtained from the respective authorities of dental colleges of above specified region and informed consent was taken from private practitioners whether independent clinic-based or hospital based dental 
Knowledge and Attitudes Related to Dental \& Healthcare Ethics Among Dental Practitioners in Delhi, India: A Cross-Sectional Questionnaire Study

surgeon. The adapted questionnaire was a selfadministered semi-structured one closed ended questions; designed to access participant's knowledge, attitude and practices in the sphere of health care ethics and was developed by taking guidance from the previous literature regarding ethics and laws in dentistry. [4-6]

A pilot study was conducted for the validation of designed questionnaire within a selected group of dental health care professionals who were asked to fill in the questionnaire and return with comments and criticisms. The required necessary modifications were made in final questionnaire.

On the predecided days, the investigator visited clinics, hospitals and dental colleges according to area distribution for getting the questionnaire filled. The participants were asked to respond to each item according to the response format provided in the questionnaire. Completed questionnaire with results were compiled and analysed statistically.

\section{ReSUlts}

The age of the participants in the study was ranged from 23-72 years with mean age of 34.2 years. Out of total 500 participants, $179(55.8 \%)$ were males and $221(44.2 \%)$ were females. Three hundred and forty participants were qualified with postgraduate degrees and only 172 participants were undergraduate. Of all the participants, 275 participants had a maintained clinical [practice for $<5$ years, 104 from 5-10 years, 86 from $10-20$ years and only 35 participants were there who had clinical practice of $>20$ years.

Table1. Characteristics of Study Participants

\begin{tabular}{|c|c|c|}
\hline Gender & $\begin{array}{c}\text { Number of } \\
\text { participants }\end{array}$ & $\begin{array}{c}\text { Percentage of } \\
\text { participants }\end{array}$ \\
\hline Male & 279 & 55.8 \\
\hline Female & 221 & 44.2 \\
\hline \multicolumn{2}{|c|}{ Qualifications } \\
\hline BDS & 152 & 30.4 \\
\hline MDS & 348 & 69.6 \\
\hline \multicolumn{2}{|c|}{ Years of Clinical Practice } \\
\hline <5 years & 275 & 55 \\
\hline 5-10 years & 104 & 20.8 \\
\hline 10-20 years & 86 & 17.2 \\
\hline$>20$ years & 35 & 7 \\
\hline
\end{tabular}

Table 2 Dentists responses regarding knowledge on Dentist Act and dentists (Code of Ethics) regulation

Table2. Knowledge Regardimg Dentist Act and Dentists (Code of Ethics) Regulation

\begin{tabular}{|c|c|c|}
\hline \multicolumn{3}{|l|}{ 1. The dentist act was given in the year } \\
\hline a. 1948 & 340 & 68 \\
\hline b. 1956 & 48 & 9.6 \\
\hline c. 1954 & 51 & 10.2 \\
\hline d. Don't know & 61 & 12.2 \\
\hline \multicolumn{3}{|c|}{ 2. The dentists (code of ethics) regulation was given by } \\
\hline a. Indian Council of Medical Research & 19 & 3.8 \\
\hline b. Dental Council of India & 390 & 78 \\
\hline c. Indian Dental Association & 51 & 10.2 \\
\hline d. $\quad$ Don't know & 40 & 8 \\
\hline \multicolumn{3}{|c|}{ 3. The dentists (code of ethics) regulation first came into force in } \\
\hline a. 1948 & 139 & 27.8 \\
\hline b. 1956 & 109 & 21.8 \\
\hline c. 1976 & 90 & 18 \\
\hline d. Don't know & 162 & 32.4 \\
\hline \multicolumn{3}{|c|}{ 4. The dentists (code of ethics) regulation was revised in the year } \\
\hline a. 2000 & 150 & 30 \\
\hline b. 2015 & 72 & 14.4 \\
\hline c. 2014 & 143 & 28.6 \\
\hline d. Don't know & 135 & 27 \\
\hline \multicolumn{3}{|l|}{ 5. There are _ principles of ethics } \\
\hline a. 3 & 39 & 7.8 \\
\hline b. & 119 & 23.8 \\
\hline c. & 212 & 42.4 \\
\hline d. Don't know & 130 & 26 \\
\hline \multicolumn{3}{|c|}{ 6. One of the following is not a principle of ethics } \\
\hline a. Veracity or truthfulness & 25 & 5 \\
\hline b. $\quad$ Confidentialty & 71 & 14.2 \\
\hline c. Punctuality & 301 & 60.2 \\
\hline Don't know & 103 & 20.6 \\
\hline
\end{tabular}


Knowledge and Attitudes Related to Dental \& Healthcare Ethics Among Dental Practitioners in Delhi, India: A Cross-Sectional Questionnaire Study

About $68 \%$ of the participants in the study knew that the Dentist act was given in the year 1948 and $390(78 \%)$ were actually aware that the dentists (Code of Ethics) regulation was given by Dental Council of India. And for the question regarding the year in which this regulation came into action, only $18 \%$ knew that the year was 1976, also, about $29 \%$ were actually aware that

Table3. Knowledge Regarding Unethical Practices this code was revised in 2014. Approximately $42 \%$ rightly said that there are six principles of ethics, and $60 \%$ were able to identify that punctuality was not one of them

Table 3 Participants response regarding unethical practices

1. Dentists can use abbreviations of memberships in associations or organizations as a suffix to their names

\begin{tabular}{|l|l|l|}
\hline a. True & 200 & 40 \\
\hline b. False & 240 & 48 \\
\hline c. Don't know & 60 & 12 \\
\hline 2. It is not mandatory to offer free consultations to fellow dentist and their immediate family \\
\hline a. True & 256 & 512 \\
\hline b. False & 191 & 38.2 \\
\hline c. Dont know & 53 & 10.6
\end{tabular}

3. It is unethical for a dental surgeon to refuse a treatment because the patient is HIV positive or suffering from any other contagious disease

\begin{tabular}{|c|c|c|}
\hline a. True & 389 & 77.8 \\
\hline b. False & 74 & 14 \\
\hline c. Don't know & 37 & 7.4 \\
\hline
\end{tabular}

4. According to the revised code, it is not unethical to advertise a dental clinic

\begin{tabular}{|l|l|l|}
\hline a. $\quad$ True & 222 & 44.4 \\
\hline b. $\quad$ False & 232 & 46.5 \\
\hline c. $\quad$ Don't know & 46 & 9.1 \\
\hline 5. According the revised
\end{tabular}

5. According to the revised code, it is not unethical to use a dentist's name in commercial products like toothpastes, toothbrush, etc.

\begin{tabular}{|l|l|l|}
\hline a. True & 138 & 27.6 \\
\hline b. False & 289 & 51.8 \\
\hline c. Don't know & 73 & 14.6 \\
\hline 6. According to the revised code, it is
\end{tabular}

6. According to the revised code, it is not unethical to affix a signboard in chemist shop or in other places where the dentist does not reside or work

\begin{tabular}{|c|c|c|}
\hline a. True & 190 & 38 \\
\hline b. False & 259 & 51.8 \\
\hline c. Don't know & 51 & 10.2 \\
\hline
\end{tabular}

7. It is not ethical for a dental surgeon to supply or sell drugs in his clinic

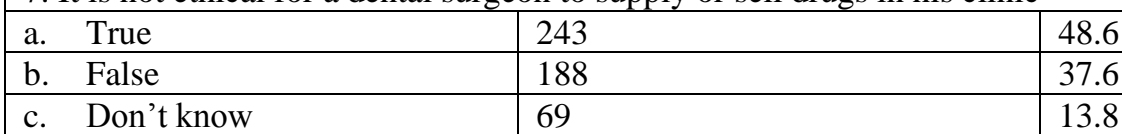

8. According to the revised code, it is not ethical for a dental surgeon to receive gifts from pharmaceutical companies

\begin{tabular}{|c|c|c|}
\hline a. $\quad$ True & 277 & 55.4 \\
\hline b. False & 160 & 32 \\
\hline c. Don't know & 63 & 12.6 \\
\hline
\end{tabular}

Table 3 describes the responses of study participants regarding unethical practices. $48 \%$ of the dental practitioners rightly marked that it was unethical to use the abbreviations of memberships in associations or organizations as a suffix to their names. About $51 \%$ were aware of the fact that it was not mandatory to offer free consultations and treatment to the fellow dentist and their immediate family. About more than two-thirds (78\%) of the participants correctly marked that it was unethical for a dental surgeon to refuse a treatment because the patient was HIV positive or suffering from any other contagious disease. About $45 \%$ knew that according to the revised code, it was not unethical to advertise a dental clinic provided that decorum was maintained. About 58\% dental practitioners in the study were aware of the fact that it was unethical to use a dentist a dentist's name in commercial products such as toothpaste and toothbrush and approximately $52 \%$ were in lieu of the fact that affixing a sign board in chemist 
Knowledge and Attitudes Related to Dental \& Healthcare Ethics Among Dental Practitioners in Delhi, India: A Cross-Sectional Questionnaire Study

shop or in other places where the dentist doesn't reside or work was unethical. About $38 \%$ were aware that it was not unethical for a dental surgeon to supply or sell drugs related to dentistry in his clinic and about 55\% knew that it was not ethical for a dental surgeon to receive gifts from pharmaceutical companies.

Table4. Participants' Knowledge of Healthcare Ethics

1. How important is knowledge of ethics to you in your work?

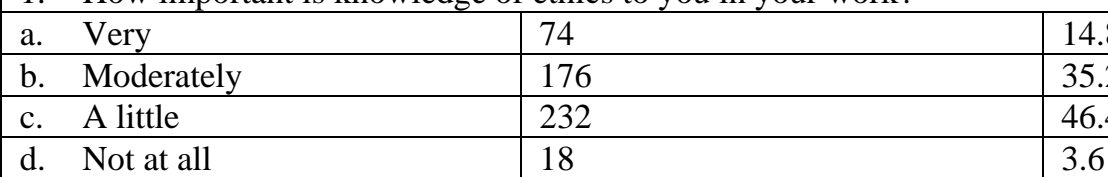

2. Do you entertain patients' questions during their visits?

\begin{tabular}{|c|c|}
\hline a. Yes & 411 \\
\hline b. No & 89 \\
\hline
\end{tabular}

3. How often do you come across any ethical issues?

\begin{tabular}{|c|c|c|}
\hline a. Daily & 101 & 20.2 \\
\hline b. Weekly & 57 & 11.4 \\
\hline c. Monthly & 59 & \\
\hline d. Yearly & 140 & 28 \\
\hline e. $\quad$ Never & 143 & 28. \\
\hline
\end{tabular}

4. How often do patients ask you about their diagnosis

\begin{tabular}{|c|c|c|}
\hline a. Never & 21 & 4.2 \\
\hline b. $\quad$ Seldom & 89 & 17.8 \\
\hline c. Always & 390 & 78 \\
\hline
\end{tabular}

5. How often do you discuss your daily cases with your colleagues?

\begin{tabular}{|l|l|l}
\hline a. Seldom & 196 & 39.2 \\
\hline b. Always & 304 & 60.8
\end{tabular}

6. Have you taken informed consent?

\begin{tabular}{|c|c|c|}
\hline a. No & 19 & 3.8 \\
\hline b. Verbal & 91 & 18.2 \\
\hline c. $\quad$ Signed & 390 & 78 \\
\hline
\end{tabular}

Only about $15 \%$ participants of the study considered that it is very important to have knowledge of ethics in their work otherwise about $76 \%$ of the participants considered moderately or a little important to know about work ethics. Around $82 \%$ of the dentists included in the study marked that they entertain patient's questions during their visits. Only about 20\% dental practitioners come across any ethical issues on daily basis otherwise about $57 \%$ dental practitioners in the study either had it once in a year or never had any ethical issue. In a clinical practice, $78 \%$ dental practitioners face patient's questions regarding their diagnosis. About $61 \%$ dental practitioners marked that they always discuss their daily cases with their colleagues. Nearly $78 \%$ of the dental practitioners in the study agreed that they take informed consent in their practice.

Table5. Attitudes of Participants Towards Healthcare Ethics

1. Doctors know the best irrespective of patients' opinion

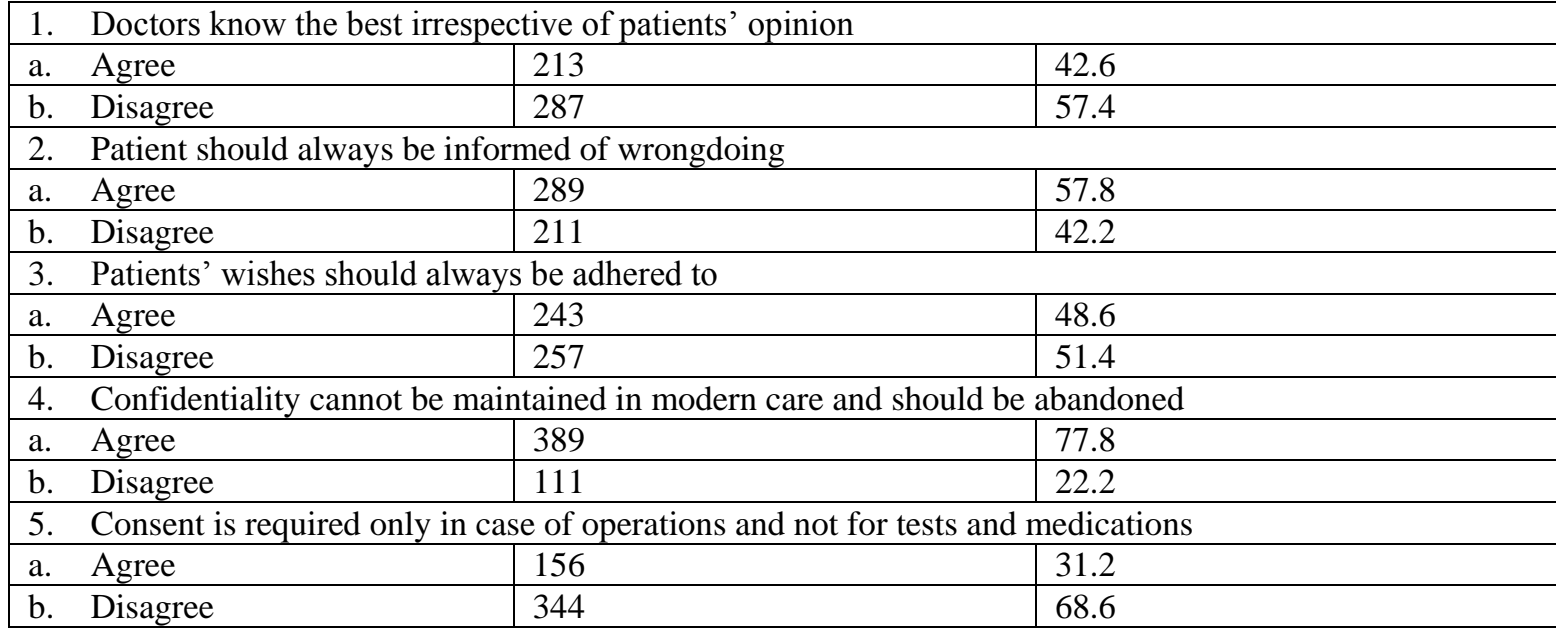


Knowledge and Attitudes Related to Dental \& Healthcare Ethics Among Dental Practitioners in Delhi, India: A Cross-Sectional Questionnaire Study

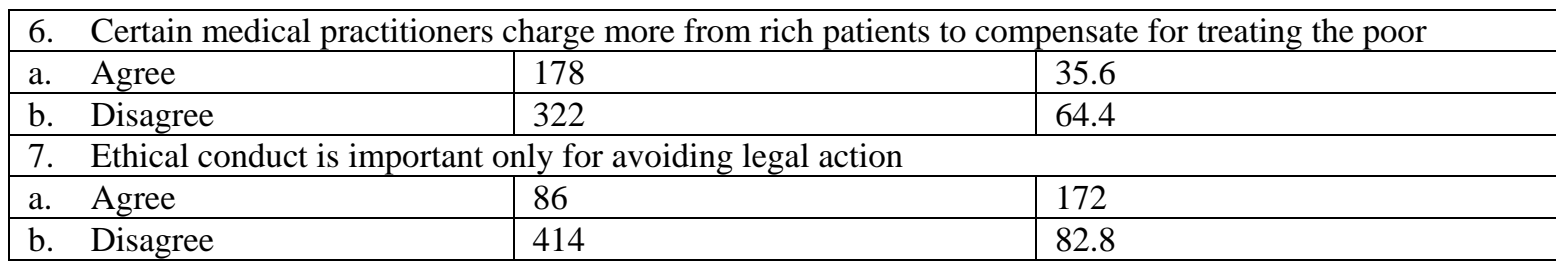

Nearly $43 \%$ practitioners believed that they knew best, irrespective of the patient's opinion. In case of any wrongdoing in treatment, around 58\% of participants always informed their patients. Around $49 \%$ practitioners agreed they adhere to patient's wishes. Nearly $78 \%$ practitioners agreed that confidentiality cannot be maintained in modern care and should be abandoned. About $69 \%$ dentists disagreed that consent is required only in case of operations and not for tests and medications. Only about $36 \%$ participants agreed that certain medical practitioners charge more from rich patients to compensate for treating the poor. About $83 \%$ participants disagreed that ethical conduct is important only for avoiding legal action.

\section{DISCUSSION}

The present study was an appreciable effort to investigate knowledge and attitude of dental practitioners with dental and healthcare ethics. This is the one of the first studies of its kind to assess the knowledge and attitudes related to dental \& healthcare ethics among dental practitioners. Most of the participants welcomed with gesture as well as appreciated the study and had good knowledge regarding Dentist act, Code of ethics and healthcare ethics.

$18 \%$ of the participants were aware that the dentists (code of ethics) regulation came into action in 1976. Ad about $29 \%$ knew that code was revised in 2014. This difference was stastically highly significant due to the fact that it has been done recently. It is mandatory and duty of every registered dentist to read, to understand and to abide by code of ethics' [3]

Almost half of the participants were not aware that it was unethical to use abbreviations of memberships in association or organisations as a suffix to their names that indicates their lack of knowledge regarding dental ethics which is a part of Public Health Dentistry in undergraduate syllabus. [7]

Nearly $78 \%$ correctly answered that it was unethical for a dental surgeon to refuse a treatment because the patient was HIV positive, which liaise with the findings in literature. [8] Almost 48\% participants didn't know that it was unethical for a dental surgeon to supply or sell drugs in his practice as long as there was exploitation of the patients. [3]

Clearly, dental practitioners have ethical dilemmas of different levels. This probably explains their level of practice and specialisation field.

The participants had obtained their healthcare ethics knowledge from different sources. Very few participants pointed the importance of knowledge of ethics in their work that could perhaps only those who had encountered ethical issues might have explored other sources of knowledge.

It was a god fact that about $82 \%$ dentists entertain patients' questions during their visits indicating the importance of understanding of dental treatment procedures by the patients and their own decision to choose particular treatment modality. And a good fact too, patients asked about their diagnosis from $78 \%$ dental practitioners that means dentist and patient have quality conversation on their visits and reduce the chances of ethical issues.

In the present study, about $78 \%$ responded correctly that they take signed informed consent which provides a platform for dental practitioners to create a good patient-clinician relationship by communicating with the patient regarding the details of the treatment, précising the information to the specific needs and understanding of the patient and most importantly, it also allows the patient to express his opinions/ concerns, builds patient's trust/ confidence on the dentist as they feel they are in control of the decisions in their treatment. [9]

Most of the dental practitioners knew about many issues related to ethical practice such as adherence to patients' wishes, confidentiality, caring attitude of practitioners and the need to obtain consent for procedures can be dedicated to their differential training at various levels.

Most of the healthcare ethics expertise in India is concentrated in research ethics, in institutional practice or in corporate hospitals. The existence of clinical ethical committee in every state that can focus on private dental practitioners is very 
Knowledge and Attitudes Related to Dental \& Healthcare Ethics Among Dental Practitioners in Delhi, India: A Cross-Sectional Questionnaire Study

important for moral deliberations on clinical cases. We suggest that dental practitioners be trained to use different methods of deliberations or moral issues [10] involved in clinical cases- a standard practice in western medical training.

\section{CONClusion}

The present study indicates that the knowledge and attitudes related to dental $\&$ healthcare ethics among dental practitioners was appreciable, but lack the sensitivity to resolve these dilemmas. It would be beneficial to address this issue in a meaningful and practical manner. Although recommendations have been made in Dentist act and code of ethics to alter their behaviour but true improvement can be seen after changes in legislation and practice policies, also, the incorporation of an ethical practice curriculum in the initial period of training programmes would be advantageous.

\section{REFERENCES}

[1] Berggren U., and Lindhe A. Dental fear and avoidance: a comparison of two modes of treatment. J Dent Res 1984; 63(10):1223-1227.

[2] Agich GJ. What kind of doing is clinical ethics? Theor Med Bioeth.2005;26(1):7-24.

[3] The Gazette of India Extraordinary, Part III, Section 4. Revised Dentists (Code of Ethics) Regulation 2014, Dental Council of India Notification; June, 2014.
[4] Anup N, Himanshu K, Gautam B, Sonia P, Swasti T. Knowledge, attitude \& practices regarding Ethics \& Law amongst medical and dental professionals in Rajasthan - A Questionnaire study. IOSR Journal of Dental and Medical Sciences May 2014; 13(5): 102109.

[5] Chandrashekhar J, Seby JG. Knowledge, attitudes and practices related to healthcare ethics among medical and dental postgraduate students in south India. Indian J Med Ethics April-June 2014; IX (2):99-104.

[6] Kiran KM, Walia R, Chaitra Devi TM, Das M, et al. Knowledge, Attitudes and Practice about Research Ethics among Dental Faculty in the North India. Journal of International Oral Health 2015; 7(Suppl 2):52-56

[7] Soben P. Essentials of Preventive and Community Dentistry. 3rd ed. India: Arya (Medi) Publishing House; 2006.

[8] Prasad S, Menon I, Dhingra C, Anand R. Awareness of consumer protection act among dental health professionals in dental schools of Ghaziabad, India. Oral Health Dent Manag 2013;12:262-8.

[9] Kotrashetti VS, Kale AD, Hebbal M, Hallikeremath SR. Informed consent: A survey of general dental practitioners in Belgaum city. Indian J Med Ethics 2010;7:90-4.

[10] Steinkamp NL. European debates on ethical case deliberation. Med Health Care Philos. 2003;6(3):225-6.

Citation: Dr. Jyoti Chopra. Knowledge and Attitudes Related to Dental \& Healthcare Ethics Among Dental Practitioners in Delhi, India: A Cross-Sectional Questionnaire Study. ARC Journal of Dental science. 2019; 4(1):10-15. doi:dx.doi.org/10.20431/2456-0030. 0401004.

Copyright: (C) 2019 Authors. This is an open-access article distributed under the terms of the Creative Commons Attribution License, which permits unrestricted use, distribution, and reproduction in any medium, provided the original author and source are credited. 